\title{
Getting students to see the light
}

Joe Schuch, Zhouling Wu

Joe H. Schuch, Zhouling Wu, "Getting students to see the light," Proc. SPIE 2525, 1995 International Conference on Education in Optics, (13 October 1995); doi: 10.1117/12.224003

Event: SPIE's 1995 International Symposium on Optical Science, Engineering, and Instrumentation, 1995, San Diego, CA, United States 
Getting students to see the light

Joseph H. Schuch and Z. L. Wu

Eastern Michigan University, Department of Physics and Astronomy

Ypsilanti, MI 48197, USA

\begin{abstract}
Currently in the United States as well as many other countries, the percentage of college students who are interested in science and engineering is decreasing. Can optics, being an area of physics which has so many applications to everyday life, be helpful to reignite student interest? In this paper we address problems related to this falloff of student interest and discuss their possible solutions. In particular, efforts are made to integrate existing techniques for general physics education into optics courses at the introductory level.
\end{abstract}

Keywords: optics education for undergraduates, classroom environment and laboratory demonstration, relations between students and professors, research in optics for undergraduates, Peer Instruction

\title{
1. INTRODUCTION
}

Every year, a large number of American high school graduates manage to survive their often inadequate pre-college education with their desire and zest for science left intact. Approximately half a million of these students will go on to take introductory science courses at the college level. Unfortunately, strong evidence suggests that between 1966 and 1988 the proportion of college freshpersons planning to major in science fell by almost half. 1 Even more disturbing is the reality that after taking introductory courses, students continue to drop out of the science fields. In fact, one-third to one-half of freshpersons who initially demonstrated an interest in science discontinue their pursuit of a science degree in favor of other career choices. 2

Many different factors are responsible for this decline in the enrollment of students in science and engineering. Obviously, some factors like the ups-and-downs in the economy (and hence the different job markets for science majors) are out of the control of colleges and universities. In this paper, we focus our attention on what can be done at colleges and universities to improve the situation. We address the problems related to the reduced interest of students in science and then discuss the possible methods to reverse their migration into other disciplines by rekindling their interest. We begin with discussions of general physics education, which has been documented in detail by various authors, $2-5$ and then examine the possibility of unifying existing techniques for general physics education into teaching optics courses at the introductory level. The key point is, can optics, being one of the most beautiful areas of physics and having so many applications to everyday life, make a difference in terms of increasing student interest, and hence their enrollment, in science and engineering?

\section{COMMON PROBLEMS IN COLLEGE PHYSICS CLASSROOMS}

In the last several decades, curricular devices and instructional formats have been invented and reinvented by succeeding generations. However, the efforts have produced few teaching innovations that have had a lasting impact on physics education. 3 This is not to say that the science community has nothing to show for itself in the past few decades. Indeed, the infusion of material resources and cultural support have substantially strengthened the scientific community and contributed to scientific innovation. The problem, however, is that educational reform in science has been neither mainstreamed nor sustained. 4 This very fact has led to many common problems in college physics classrooms, some of which have been documented in great detail. 2 It is noteworthy to point out that these problems exist also for optics courses, in particular those at the introductory level.

\subsection{Problem 1: The Lack of Community}

Many introductory physics classes are absent of a sense of community. 2 Particularly in most optics classes, lecture is the primary instructional practice used in the classroom, which unfortunately does not lead itself to open communication 
between students. Students are simply being "talked at." They do not have the opportunity to articulate their subject matter directly with one another. In other words, students have no opportunity to get practice at "talking optics" -- that is, students have no avenue for which to clearly present what they have learned to peers and professors. They may honestly believe they understand a concept but find they are unable to explain their thinking to others and thus do not clearly understand what they thought they had mastered. This inability to explain one's thinking to others is a result of the lack of community in the classroom. Combined with the lack of interchange between the professor and student, this lack of community produces a passive classroom experience. Passive lectures, in turn, can prove to be particularly dangerous for students who believe that if they can follow the professor, then they have mastered the material. Optics courses organized to give students premasticated information simply to mimic and apply to problems account for a large part of the lack of student involvement. As an alternative, allow students to be exposed to conceptual problems where answers can not be found directly from the text book or a particular formula. Then, encourage students to try to find solutions to the problems on their own and help them to understand the mistakes they make along the way. In this way, students will begin talking among themselves and with the professor about these problems. Students will begin "talking optics" which will better help them understand the important concepts involved in problems. A strong communal environment will begin to flourish as students actively participate in classroom discussions about these conceptual problems.

\subsection{Problem 2: The Problem with "Problem Solving"}

Many introductory physics classes seem to focus exclusively on "problem solving . 2 This appears to be the case in most optics classes as well. Students are found to primarily focus on the kinds of problems they would encounter on exams and not at all on a general understanding of the concepts. They want to know "what equals what" and solve for an answer. The elegance of problem solving is often lost because students fail to understand what concepts are at work. Instead, they become obsessed with looking for missing variables to plug into equations they have memorized. When optics classes are taught simply using a quantitative approach, students are no longer taking an optics class but an applied mathematics course instead. Optics is a qualitative field of study that uses mathematics as tool to help interpret its underlying concepts.

Furthermore, in optics classrooms, students are found not to ask as many "why" questions, but prefer to ask "how-doyou-solve-for" questions. As long as professors continue to assess students by asking quantitative questions, then students will get the message that they should only focus on problem solving. Hence, they will continue to ask the "how-do-yousolve-for" questions and miss the beauty behind the more important "why" questions. To help students better comprehend concepts, time must be allotted for them to simply read the text. Students should be expected to ask questions about the reading as well as be expected to answer qualitative questions on assessments. Without these expectations, students will just memorize the summary page of equations and practice their "plugging and chugging." The goal should be to use a conceptual approach which in turn will facilitate the learning of problem solving techniques.

\subsection{Problem 3: The Negative Side of Grades}

The fixation of students on grades is another problem which plagues the teaching of optics. Due to the frequent use of grading students on a curve, where student grades are determined not by a set standard but by how well students perform in relation to their peers, the spirit of enjoyment of optics is diminished. The message (though often not intended) seems to be that no matter how hard a student works -- so long as other students work just as hard or have more natural ability or experience -- the student has no chance to improve their grade. As a result, a sense of competition is created which automatically precludes any desire to work with or help other people. This problem takes its toll not only in the classroom environment but in the real world as well. When students some day hold jobs in technologically-based companies where they will be assigned to teams in order to tackle large projects, they will suffer since they have had no training in working collectively. In fact, their experience will have taught them to fear cooperation. Even worse, they will have learned that another person's intellectual achievement can be detrimental to their own.

\subsection{Problem 4: The Linkage Between Concepts and The Real World}

Another common obstacle on the road to understanding for students is the lack of identifiable goals and the absence of linkage between concepts to the real world. ${ }^{2}$ In optics, students often march through chapters, do the required work, but never manage to dig deeper. Professors rarely tie together information from more than one chapter and often fail to make connections between concepts and the real world. Lectures often do not seem to build upon one another and sometimes there is no indication of a linear movement through a group of concepts. Furthermore, exams usually test only the most important laws of optics. Students are seldom required to interrelate concepts or to try and understand the "bigger picture." To help remedy this problem, a "road map" may be useful to see how each individual property and theory is related to the big picture 
as well as to the real world. If creative, innovative students are to be retained in greater numbers, professors are going to have to give them more of a sense of the goals, the structure, and the way optics relates to the real world so that they can exercise their curiosity and critical thinking powers. For example, when a student looks in a fishbowl, the fish appears to be closer to the surface than it actually is -- but why? Here is a real world phenomenon that occurs quite naturally. It can easily be linked to concepts from geometrical optics. Students better relate to the fish in the fishbowl than to reading a text on the law of refraction. But when the two are combined, not only does the understanding of students increase, but students come away with a meaningful experience that links their curiosity with their powers of critical thinking.

\subsection{Problem 5: Knowledge and Creativity}

The transfer of knowledge from professors to students is no doubt an important part of the education process. However, if we look deeper into the problem, we find that teaching would never be effective if there were no active learning done by the students. And further, if there were no critical thinking and creative activity involved in the teaching-learning process, i.e. students simply following professors, there would be no progress in science and no improvement in our knowledge from generation to generation. But where is the balance a professor should take in an optics class? How should teachers stimulate the interest of students and convey more enthusiasm to them? If teachers can convince students to learn actively and think critically and creatively, the major part of education will be done. After all, knowledge is learned rather than taught.

\subsection{Problem 6: Student-Professor Relations}

The lack of communication between professors and students often creates an awkward learning atmosphere which inhibits students from learning and professors from teaching at their maximum potentials. If students are not made to feel comfortable asking questions during class, how can they be expected to learn all of the material? It is not reasonable to assume that a student who remains silent throughout an entire class has fully comprehended all that has been taught. A professor will not truly know how a student is doing until the first exam or alternative assessment is given. By then, it may be too late for a student who has no idea what is going on and does not feel comfortable talking with the professor. If there is a problem with content or even the course itself, students should be able to air their concerns to the professor during the course so that the delicate teaching-learning balance does not get out of whack. When a professor receives student evaluations two months after the course, there is no way he or she can help those particular students.

Of course, communication works both ways. It is not just the responsibility of the student to communicate with the professor. The professor must also take an active role in the communication process. If students look puzzled when going over a difficult concept, professors need to ask students what part of the concept they are having trouble with. Similarly, if quite a few students seem to be struggling after an exam, the professor should give students the opportunity to find out what went wrong. Students are the most valuable source of information for professors in terms of how well they (the students) are learning the material. Many professors choose not to tap this source which only serves to limit their teaching capabilities.

\section{SOME INNOVATIVE APPROACHES FOR OPTICS EDUCATION}

\subsection{Peer Instruction in the Optics Classroom}

In 1989 Gordon McKay professor of applied physics Eric Mazur at Harvard University read an article in the American Journal of Physics that contained a diagnostic test to assess understanding of Newtonian mechanics. He gave the exam to 300 of his introductory physics students, and the results shocked him. He found that what he thought students were understanding, they clearly did not understand. Mazur had been teaching the Physics 11 course at Harvard for eight years and until then had depended chiefly on the traditional lecture format style of presentation. But after this enlightening event, he quickly reformed his teaching ways. In 1991, Mazur implemented one of his teaching innovations called Peer Instruction, a pedagogical method that actively involves students in the teaching process. 5

Peer Instruction works in the following manner. Mazur breaks down his Physics 11 lectures into a series of digestible snippets, emphasizing concepts and ideas and avoiding lengthy equations and derivations. Every 15 minutes an overhead projector flashes ConcepTests, as Mazur calls them, on a screen. These short conceptual questions generally require qualitative rather than quantitative answers. Students get one minute to think about each ConcepTest then punch their answers into hand-held computers. They have another minute to convince their neighbors of their logic. Chaos erupts as everyone begins to engage in earnest discussion: bodies twist, heads shake, and hands gesticulate. The buzz continues until Mazur calls time and asks students to plug their revised answers into the computer. They also record their confidence levels -pretty sure, not quite sure, or just guessing. Responses are uninhibited because the ConcepTests are not graded. The 
computer instantly shows the percentage who answered correctly. This approach to teaching general physics can also be applied to courses in optics. An optics example of a ConcepTest for Fermat's Principle of Least Time is shown in the following box. 6

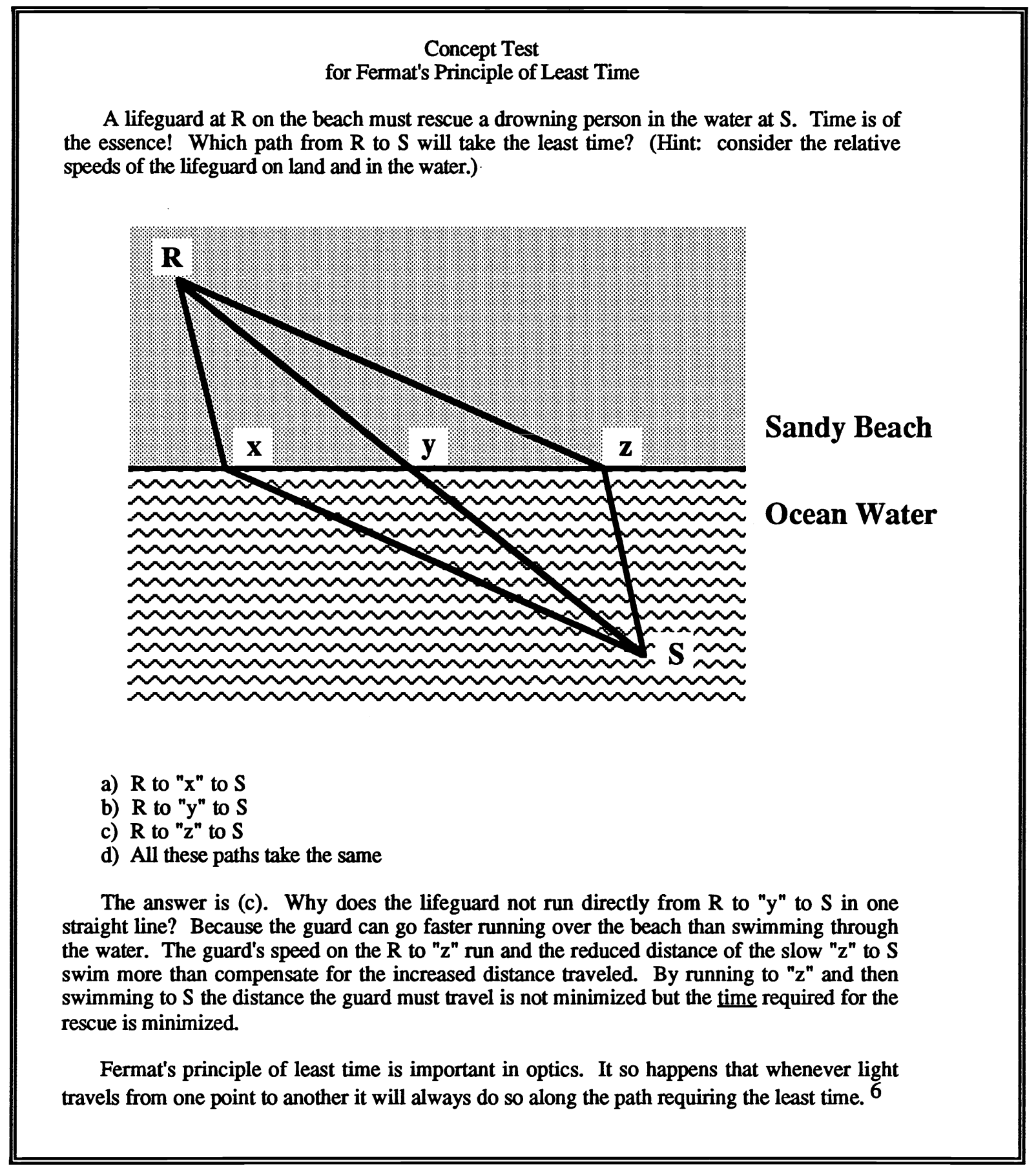

The convince-your-neighbor arguments systematically increase both the percentage of correct answers and the confidence of students. Because students are vividly aware of the difficulties involved in grasping a concept, they are often more effective at explaining an idea than professors are. If the professor is not satisfied with the performance of his students, he slows the 
pace, providing more detail on the current subject, and then reevaluates with another ConcepTest. When the results indicate mastery of the concept, the professor moves on to the next topic.

The Peer Instruction approach to teaching general physics can be readily applied to optics courses. It clearly establishes a sense of community as students are able to practice "talking optics" with one another during ConcepTest discussion periods. Students are expected not only to learn what is being taught during the class period, but then also have to articulate what they have learned to their peers. Since students are actively involved in the learning process, very few students drop out. Furthermore, the duration of Peer Instruction is rather short allowing for frequent intervention on the part of the professor. Using ConcepTests also allows the professor to effectively control the pace of the class since he or she is constantly receiving input about student understanding.

Peer Instruction also de-emphasizes "problem solving." Instead, this approach acknowledges that understanding concepts is the key to being a successful problem solver. With this approach in place, students are more apt to ask the "why" questions which in turn allows them to see and understand the beauty behind problem solving.

\subsection{Novel Channels for Student-Professor Communications}

For better communication between students and professors, novel methods need to be developed and used. One way to keep the communication channel open is to have students elect a representative committee who meet regularly with the professor to air student concerns. Professors can also use anonymous questionnaires to find out student opinions -- in particular, their critical comments about the course and the teaching methods used. Since students tend to back away when given opportunities to talk face-to-face with professors, these anonymous approaches can be used so that students feel more comfortable with the communication process.

In addition, professors can make themselves available to students in a variety of other ways. For example, a professor might have a lunch or dinner meeting with students once in a while in an informal atmosphere that would allow students to talk about the course or anything else they might have in mind. An informal atmosphere can "humanize" a professor for those students who might otherwise be intimidated. Professors should also let students know that everyone makes mistakes, and that making mistakes is one way to make progress. They should encourage students to ask all kinds of questions, and create an environment in class so that students are not afraid to ask "stupid" questions -- after all, no question is a stupid one.

Another avenue professors now have is communication via the internet. As more and more residence halls become equipped with computers, communication on the network becomes a lot easier and more efficient for both students and professors. With computers, professors can hold office hours, display homework hints, correct mistakes and/or omissions from lectures, and answer all kind of questions from students. The computer adds a new dimension to the opportunity students may have to communicate with professors.

Furthermore, in talking about student-professor communications we should emphasize one issue which is often ignored -students who disappear from class, i.e., drop out. ${ }^{2}$ In many universities and colleges, drop cards are handled bureaucratically by staff in registration. There is therefore little opportunity for retrieving the failing students and/or soliciting their views about the particular courses they dropped. A better alternative would be to have course instructors sign drop cards so that there is an opportunity for an "exit interview". It would thus allow the professor and the student to have a conversation about the course, the student's career goals and his or her alternative plans.

Finally, a more unique approach to breaking down the barriers that seem to build up between students and professors is to put them on an equal playing field -- that is, create an atmosphere where students and professors are viewed as colleagues. The typical dominant role of the professor is thus reduced to the role of an equal. In this way, students will feel more at ease in approaching their professors.

\subsection{Optics in Everyday Life}

Compared with other disciplines of science, optics has a unique advantage in terms of stimulating the interest of students. Light is everywhere in everyday life -- from the sunny blue sky, the rainbow and the sunbow to the mirage phenomenon and the iridescent colors seen on the thin films of soap bubbles. While students are usually attracted to this beautiful side of optics, it is the responsibility of professors to guide students to make connections between what they see (and may have taken for granted) and what they learn in the classroom. The goal for students should be to develop research skills which will help them to better make sense of the balance between what they learn in the text book and what they observe happening in the 
world around them. Students should be encouraged to develop the ability to carefully observe phenomena. With these observations, students need to learn how to analyze them and discover what principles are at work. Only when students can understand what they have observed can they use that important information to apply to the real world around them.

\subsection{Laboratory Demonstration}

Laboratory has been used extensively in optics education. What is emphasized here is the difference between a laboratory course in optics and a laboratory demonstration for optics. The former is for students with some optics background to gain hands-on experience and hence understand better the knowledge they have learned, while the latter is designed for students who are wandering in front of sciences and have not made up their mind about where to go yet. Demonstrations are used to attract the attention of students, to expose them to the beauty of optics and to stimulate their interest in optics and ultimately the general sciences. The laboratory demonstration can follow the example of a good science museum, like the Munich Science Museum in Germany, where students can watch and/or conduct experiments purely subject to their own pleasure. It should be emphasized that there is a big difference between doing what one wants to do and what one is told to do.

\subsection{Independent Studies}

After having finished an optics course at the introductory level, students who want to go deeper into certain subfields should be encouraged to continue their studies by taking higher level courses. Meanwhile, they should also get the message that they can try to go forward without an instructor -- after all, when they get out into the real world, no instructors will be around to guide them. At this stage, independent studies appear to be a most effective training method. We offered an introductory optics course in the winter semester of 1995. After the course, four of the students signed up for independent studies in the experimental laser laboratory of the department. The activity produced not only tremendous enthusiasm in the students, which is very important for their future success, but also great progress in terms of gaining further knowledge in optics and generating research results for the laboratory.

\subsection{Undergraduate Research}

Optics is one of the richest fields for undergraduate research. Research projects can be arranged for students with almost all kinds of backgrounds, with some of them starting research activities even before the introductory optics course. In our laser laboratory we encourage as many students as possible for involvement in research and are currently offering more than ten projects for undergraduates to work on. Undergraduates working in the laboratory are coordinated by the director of the laser lab and are supervised by faculty members and a guest scientist. They are encouraged to team up with each other and with graduate students and are required to attend a weekly group meeting for reports and discussions. The results of this practice have turned out to be extremely good, and it benefits both the students and the professors. Students get the opportunity for doing real-world research. To professors, working with undergraduates is both challenging and rewarding. The reward comes not only from seeing great progress in students, but also from the many sparkling ideas formed when discussing and supervising the students. Teaching indeed is the best way of learning, and students in many cases work as great teachers without knowing that fact themselves.

\section{SUMMARY AND CONCLUSIONS}

Recently, the enrollment of students in science and engineering has been decreasing in the United States as well as many other countries. The seriousness of the problem may not yet be recognized by society, since it is currently considered that there is a surplus in the supply of scientists. However, if the trend continues, a global problem will manifest itself in the future.

In this paper, optics/physics education is taken as an example to analyze the problems in the education process which are related to the reduced interest of students in science. Possible solutions were discussed which may help to reverse the migration of students into other disciplines. In particular, the many existing techniques for general physics education need to be introduced into optics courses at the introductory level. It is believed that optics, being an area which has so many applications to everyday life, can be very helpful to increase student interest, and hence their enrollment, in science and engineering. 


\section{ACKNOWLEDGMENTS}

This work is supported in part by the Michigan State Research Excellence Fund through the Office of Research and Development and the Graduate School of Eastern Michigan University. We gratefully acknowledge the encouragement and invitation from M. J. Soileau of CREOL, the conference Chair who gave us the chance to submit this paper post-deadline and to present it at the meeting. Joseph H. Schuch expresses appreciation to his wife, Laura, and son, Timothy, for their support and patience during the course of researching and writing this paper. Z. L. Wu is in debt to P.K. Kuo of Wayne State University for his fruitful discussions.

\section{REFERENCES}

1. Kenneth C. Green, "A profile of undergraduate in the sciences", American Scientist, Vol. 77, No. 4, p. 476, 1989.

2. Sheila Tobias, They're not dumb, they're different: stalking the second tier, Research Corporation, Tucson, AZ, 1990.

3. Arnold Arons, "Uses of the past: physics curricular reform 1955-1990", Interchange, Vol. 24, No. 1\&2, p.105, 1993.

4. James Duderstadt, "Keynote address", The freshman year in science and engineering, The alliance for undergraduate education, University of Michigan Conference, p.9, 1990.

5. Sheila Tobias, Revitalization undergraduate science: why some things work and most don't, pp. 114-122, Research Corporation, Tucson, AZ, 1992.

6. L.C. Epstein, Thinking Physics, Insight Press, pp. 325-326, 1989. 